\title{
Mobile video directly observed therapy can be used to improve at-home inhaler technique in children with asthma
}

\begin{tabular}{|c|c|}
\hline & Editor: \\
\hline $\begin{array}{l}\text { Received: } 14 \text { July } 2021 \\
\text { Accepted: } 18 \text { July } 2021\end{array}$ & 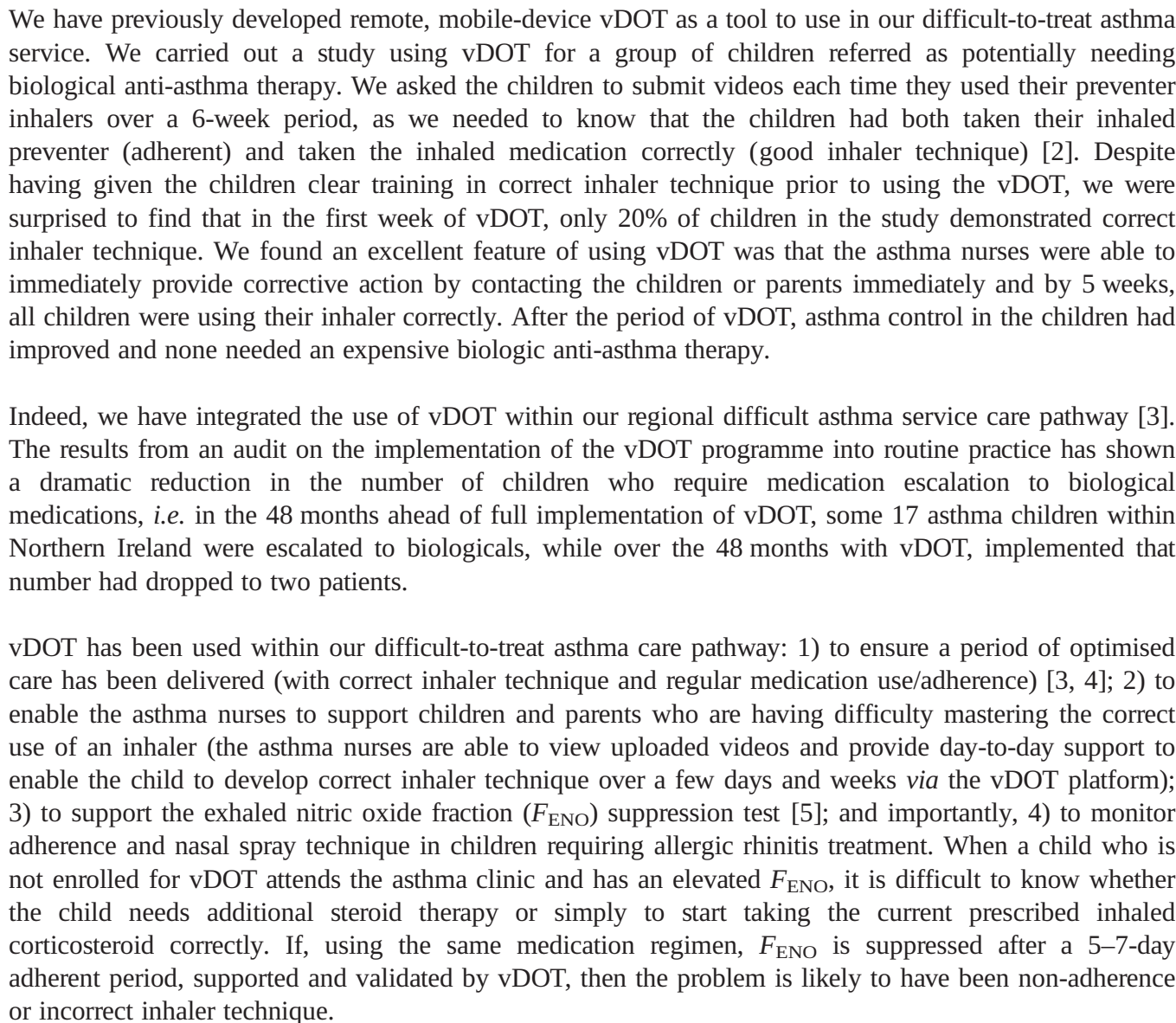 \\
\hline $\begin{array}{l}\text { W) } \\
\text { Check for } \\
\text { updates }\end{array}$ & $\begin{array}{l}\text { Shareable abstract (@ERSpublications) } \\
\text { Most children and parents have mobile smartphones that can be used to record videos while the } \\
\text { child uses their inhaler. The timed (stamped with date and time) videos can be submitted to a } \\
\text { secure repository. An asthma nurse then can review the video. https://bit.ly/2UyG11W }\end{array}$ \\
\hline & $\begin{array}{l}\text { Cite this article as: Shields MD, McElnay J. Mobile video directly observed therapy can be used to } \\
\text { improve at-home inhaler technique in children with asthma. ERJ Open Res 2021; 7: 00463-2021 } \\
\text { [DOI: } 10.1183 / 23120541.00463-2021] \text {. }\end{array}$ \\
\hline
\end{tabular}


We believe that the paper published in ERJ Open Research [1] and our study [2] suggest that the use of vDOT provides another approach or tool to improving asthma control that may be preferable to, or additional to, the use of electronic inhaler device monitors [5].

The advantages of the vDOT approach include: 1) being device independent; 2) facilitating immediate corrective action (via the vDOT platform); 3) it can be used to assess treatments for allergic rhinitis (both adherence and nasal spray technique); and 4) it provides monitoring of both correct inhaler technique and adherence (each inhalation is stamped with time and date).

Overall, we believe that the use of vDOT as described in this paper could not only be incorporated into difficult asthma care pathways but also facilitate further research into how people use inhalers over time. This could lead to improved ways of training children to master inhaler technique so that correct inhaler technique at home is assured.

Michael D. Shields ${ }^{1,2}$ and James McElnay ${ }^{3}$

${ }^{1}$ Medicine, Dentistry and Biomedical Science, Queen's University Belfast, Belfast, UK. ${ }^{2}$ Royal Belfast Hospital for Sick Children, Belfast, UK. ${ }^{3}$ Pharmacy, Faculty of Medicine, Health and Life Science, Queen's University Belfast, Belfast, UK.

Corresponding author: Michael D. Shields (m.shields@qub.ac.uk)

Provenance: Submitted article, peer reviewed.

Conflict of interest: The authors launched ( January 2017) a commercial enterprise to develop and market a vDOT solution (www.continga.co.uk).

References

1 van der Kolk A, Lammers N, Brusse-Keizer M, et al. Comparison of inhalation technique with the Diskus and Autohaler in asthmatic children at home. ERJ Open Res 2021; 7: 00215-2019.

2 Shields MD, ALQahtani F, Rivey MP, et al. Mobile direct observation of therapy (MDOT) - a rapid systematic review and pilot study in children with asthma. PLoS One 2018; 13: e0190031.

3 Morton RW, Elphick HE, Craven V, et al. Aerosol therapy in asthma-why we are failing our patients and how we can do better. Front Pediatr 2020; 8: 305.

4 O'Donoghue DB, Shields MD. A multidisciplinary approach to managing difficult to treat asthma in children. In: Forno E, Saglani S, eds. Severe asthma in children and adolescents: Mechanisms and management. Cham, Springer International, 2020; pp. 168-182.

5 Butler CA, Heaney LG. Fractional exhaled nitric oxide and asthma treatment adherence. Curr Opin Allergy Clin Immunol 2021; 21: 59-64. 